\title{
Cartilage Tympanoplasty - Anatomical and Functional Results
}

\author{
Sanae Mellouk*, Meryem Lahjaouj, Sara Halily, Yasser Hammouda, Sami Rouadi, Reda Allah Larbi Abada, \\ Mohamed Roubal and Mohamed Mahtar
}

ENT department, 20 August hospital 1953 CHU IBN ROCHD Casablanca, Morocco

Submission: November 27, 2019; Published: December 09, 2019

*Corresponding author: Sanae Mellouk, ENT department, 20 August hospital 1953 CHU IBN ROCHD Casablanca, MoroccoPortugal

\begin{abstract}
Objective: To describe the anatomical and functional results of Cartilage tympanoplasty.

Material and Methods: We realized a transversal descriptive study, involving patients operated by cartilage tympanoplasty in the otolaryngology department of Casablanca University Hospital from January 2015 to December 2018.

Results: 107 patients were involved in this study. All the operations were performed under general anesthesia using the retro auricular approach in $98.1 \%$. In $100 \%$ of the cases, the grafting material was the cartilage. The underlay technique was applied in most of the cases. The anatomical and functional results evaluated over a mean follow-up of nine months are satisfactory. The tympanic closure was obtained in $96 \%$ of cases. As a functional result, a hearing gain between 10 and $30 \mathrm{~dB}$ was obtained in $72.9 \%$.
\end{abstract}

Conclusion: Thanks to its resistance, acoustic properties and best long-term anatomical results, cartilage is the material of choice for recurrent perforation, large perforation, uncontrolled shrink pocket, tympanic membrane atelectasis and dysfunction of the Eustachian tube.

Keywords: Tympanoplasty; Myringoplasty; Cartilage; Air-bone gap; Hearing loss

\section{Introduction}

Tympanoplasty is a frequent otological surgical procedure that aims to restore the anatomical and functional integrity of the damaged eardrum. The term myringoplasty refers to type I tympanoplasty consisting of a reconstruction of the tympanic membrane without manipulation of the ossicular chain. This is one of the modalities of tympanoplasty. The main grafts used are temporal muscle fascia, conchal or tragal cartilage, and perichondrium [1]. Cartilage is the main material used for its several advantages [2]. The purpose of this work is to report the experience of the department of otolaryngology of Casablanca university hospital in type I tympanoplasty, and to evaluate the anatomical and functional results.

\section{Materials and Methods}

We realized a transversal descriptive study, involving patients operated by cartilage tympanoplasty in the otolaryngology department of Casablanca University Hospital from January 2015 to December 2018. We included in our study patients with tympanic perforation without ossicular involvement who underwent cartilage tympanoplasty and operated by senior surgeons. Patients with retraction pocket, ossicular chain involvement, lost to follow-up and incomplete records were excluded from this study. The data included: Age, sex, otological history, consultation time, circumstances of discovery, otological examination, pre-operative auditory evaluation, surgical technique and postoperative anatomical and audiometric results.

\section{Results}

The mean age in our study was 38.34 years (+/- 19.22 SD) (8 - 81 years). Most patients were female with a Male/Female ratio of 0.44 . Hearing loss and otorrhea were the main complaints that motivated medical consultation. The consultation time varies from a few days to several years, but $67.3 \%$ of patients have a history that began in childhood. Tympanic perforation was more common on the left side (48.6\%) and bilateral in $18.7 \%$ of patients. Subtotal perforations were the most common (41\%), followed by inferior perforations (15\%). The anterior edge was present in 52 patients (55.6\%).

Examination of the contralateral ear showed a normal eardrum in $52 \%$ of cases, a perforation in $18.7 \%$ of cases, a retraction pocket in 16\% of cases and a Myringosclerosis in 13\% of cases. Audiometric evaluation showed conductive hearing loss in ninety cases (unilateral in 65 cases and bilateral in 25 cases) and mixed hearing loss in 17 cases. The average hearing loss was 
$47.20 \mathrm{~dB}(+/-14.86 \mathrm{SD})$. The mean air-bone gap was $28.41 \mathrm{~dB}$ $(+/-9.44 \mathrm{SD})$.

Regarding treatment, myringoplasty was conducted by a retro-auricular incision in $98.1 \%$ of cases. Per-operatively, the tympanic cavity was dry in $83.2 \%$ of cases. The mucosa was inflamed in $19.2 \%$ of cases. The ossicular chain was mobile and continuous in all patients. For myringoplasty, we used cartilage island graft with its perichondrium in an "underlay" position for all patients. Mainly conchal cartilage (71\%). We reinforced the graft with temporal fascia in $88.8 \%$ of patients. The mean follows up was nine months.

\section{Anatomical results}

Regarding the anatomical results, 103 patients had closure of the eardrum. However, three patients had tympanic retraction and, another three had cartilage displacement (Figure 1).

\section{Anatomic results}

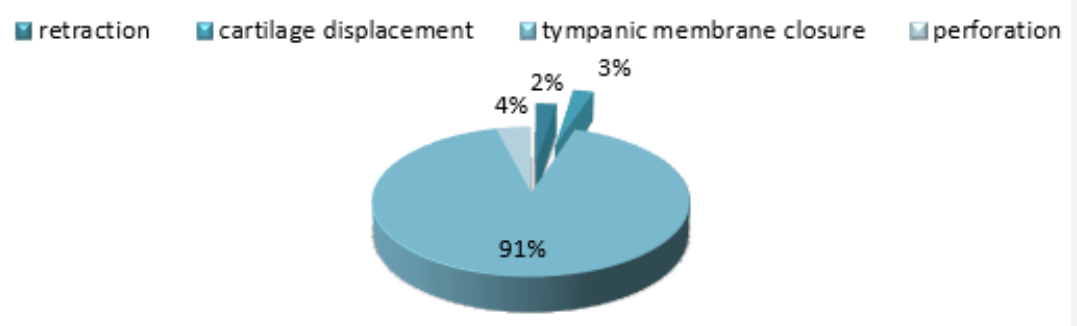

Figure 1: Anatomical results.

\section{Functional results}

Table 1: Assessment of hearing Loss and audiometric air-bone gap before and after surgery.

\begin{tabular}{|c|c|c|}
\hline \multirow{2}{*}{} & Hearing Loss & Air-Bone Gap \\
\cline { 2 - 3 } Mean (dB) & Mean (dB) & $+/-$ standard déviation \\
\cline { 2 - 3 } & $+/$ - standard deviation & $28,41+/-9,44$ \\
\hline Pre-Operative & $47,20+/-14,86$ & $15,79+/-7,25$ \\
\hline Postoperative & $32,16+/-11,21$ & $<0,001^{*}$ \\
\hline
\end{tabular}

The mean post-operative air-bone gap was $15.79(+/-7.25) \mathrm{dB}$ and the average hearing loss was $32.16(+/-7.25)$ Db. A significant improvement in hearing thresholds and air-bone gap was noted after tympanoplasty ( $\mathrm{p}<0.001)$ (Table 1$)$. An improvement in hearing (> $10 \mathrm{~dB}$ ) was noted in $75.7 \%$ of patients (Table 2 ).

Table 2: Average hearing gain in $\mathrm{dB}$.

\begin{tabular}{|c|c|c|}
\hline Average gain (dB) & Number & Percentage (\%) \\
\hline $0-10$ & 76 & 24,3 \\
\hline 30 -Nov & 78 & 72,9 \\
\hline$>30$ & 3 & 2,8 \\
\hline
\end{tabular}

\section{Discussion}

The main purpose of myringoplasty is reconstruction of the perforated tympanic membrane and improvement of hearing. The most commonly used graft materials are the temporal fascia, perichondrium and cartilage. The latter has demonstrated its advantages in many studies because of its anatomical stability, ease of sampling, and resistance to shrinkage and necrosis. Cartilage is available in enough quantity, slightly antigenic, and better tolerated by the middle ear than other grafts [1]. However, there is concern that the thickness and rigidity of the cartilage may affect functional performance [3]. Studies showed that this risk is eliminated by the refinement of the cartilage during graft preparation [4]. The ideal cartilage thickness in several studies is $0.4 \mathrm{~mm}[5]$.

Cartilage is increasingly used for recurrent middle ear infections, retraction pockets, adhesive otitis, tympanosclerotic perforations, anterior perforations, tubal insufficiency, bilateral perforations and in the pediatric population $[1,6,7]$. In our series, 
we chose cartilage for all patient for its resistance, and because perforation was often associated with Myringosclerosis. The cartilaginous graft can be harvested from two preferential sites: concha and tragus. However, we obtain a larger graft when using conchal cartilage.

The latter can be used as first line or second line if the tragal cartilage has already been removed. Tragal cartilage is used because of its flat surface, its thinness and its size adapted to small perforations [1]. The choice of cartilage type depends on the size and location of the perforation, as well as the surgeon's experience. In our series, we used conchal cartilage in 76 patients for large perforations and tragal cartilage in 31 patients for anterior and small perforations.

The perichondrium (tragal or conchal) is nowadays increasingly used as it has the advantage of being more resistant while being thin. It behaves from an impedancemetric point of view like a fascia [8]. The temporal fascia is very often chosen as a graft material in myringoplasty. Its physical qualities make it easy to use especially after spreading and drying, but its relative flexibility increases the risk of deformation in case of chronic tubal dysfunction [9]. The temporal fascia reinforced by cartilage has become a widespread technique because of the better anatomical and functional results compared to the use of the fascia alone. $[10,11]$.

Table 3: Anatomical results of included studies.

\begin{tabular}{|c|c|}
\hline Author & Tympanic Membrane Closure \\
\hline Arora 13 & $93,33 \%$ \\
\hline Kaya14 & $94,6 \%$ \\
\hline Vadiya 15 & $98,46 \%$ \\
\hline Bilgen 16 & $100 \%$ \\
\hline Our study & $96,26 \%$ \\
\hline
\end{tabular}

Table 4: Functional results of included studies.

\begin{tabular}{|c|c|}
\hline Author & Residuel Air-Bone Gap (dB) \\
\hline Simsek 17 & 13.21 \\
\hline Michel 7 & 11.7 \\
\hline Cavalière 18 & 10.66 \\
\hline Our study & 15.79 \\
\hline
\end{tabular}

In our study, 95 patients underwent myringoplasty using temporal fascia reinforced by cartilage and achieved a tympanic closure in all cases. On the other hand, the 12 patients in whom cartilage alone was used, a tympanic closure was observed in 8 cases and 4 cases retained residual perforation. Evaluation of the quality of closure of the tympanic membrane using cartilage has been studied by many authors and compared to other techniques such as fascia or perichondrium. We obtained closure of the eardrum in $96.26 \%$ of cases which is close to the literature data (Table 3) [12-15]. These authors also demonstrated better auditory results in favor of cartilage tympanoplasty when compared to other grafts. The average residual air-bone gap in our study was $15.79 \mathrm{~dB}$, slightly higher compared to other studies (Table 4) $[6,16,17]$.

\section{Conclusion}

Several parameters can influence anatomical and functional results of cartilage tympanoplasty. The age, perforation size and localization, middle ear inflammation, status of the contralateral ear, tympanosclerosis and tubal dysfunction. The impact of each factor remains difficult to determine. It is rather the combination of these factors that influence the results of cartilage tympanoplasty $[18,19]$. Thanks to its resistance, acoustic properties and better long-term anatomical results, cartilage is the material of choice in case of recurrent perforation, large perforation, uncontrolled retraction pocket, atelectasis of the tympanic membrane and eustachian tube dysfunction.

\section{References}

1. Mohanty S, Manimaran V, Umamaheswaran P, Jeyabalakrishnan S, Chelladurai S (2018) Endoscopic cartilage versus temporalis fascia grafting for anterior quadrant tympanic perforations - A prospective study in a tertiary care hospital. Auris Nasus Larynx 45(5): 936-942.

2. Dündar R, Soy FK, Kulduk E, Muluk NB, Cingi C (2014) A new grafting technique for tympanoplasty: tympanoplasty with a boomerang-shaped chondroperichondrial graft (TwBSCPG). Eur Arch Otorhinolaryngol 271(10): 2687-2694.

3. Lou Z, Lou Z H (2017) Full-thickness cartilage myringoplasty on the patulous Eustachian tube. Eur Arch Oto-RhinoLaryngol Off J Eur Fed Oto-Rhino-Laryngol Soc EUFOS Affil Ger Soc Oto-Rhino-Laryngol Head Neck Surg 274(11): 4051-4053.

4. Abdelhameed W, Rezk I, Awad A (2017) Impact of cartilage graft size on success of tympanoplasty. Braz J Otorhinolaryngol. Sept 83(5): 507511.

5. Jalali MM, Motasaddi M, Kouhi A, Dabiri S, Soleimani R (2017) Comparison of cartilage with temporalis fascia tympanoplasty: A meta-analysis of comparative studies: Cartilage Versus Fascia Tympanoplasty. The Laryngoscope 127(9): 213948.

6. Michel G, Espitalier F, Boyer J, Malard O, Bordure P (2018) Clinical and economic evaluation of minimally invasive cartilaginous palisade myringoplasty. Acta Otolaryngol (Stockh) 138(1): 10-15.

7. Alicandri Ciufelli M, Marchioni D, Grammatica A, Soloperto D, Carpeggiani P, et al. (2012) Tympanoplasty: An up-to-date pictorial review. J Neuroradiol 39(3): 149-157.

8. Min J, Kim S H (2017) Comparison of transcanal endoscopic tympanoplasty with sterile acellular dermal allograft to conventional endaural microscopic tympanoplasty with tragal perichondrium. Am J Otolaryngol déc 39(2): 167-170.

9. Dost P, Maune S (2014) Cartilage vs temporal fascia as graft material. Laryngorhinootologie 93(8): 502-503.

10. Kulkarni S, Kulkarni V, Burse K, Sancheti V, Roy G (2014) Cartilage Support for Fascia Graft in Type I Tympanoplasty. Indian J Otolaryngol Head Neck Surg 66(3): 291-296.

11. Vasani SS, Anmolsingh R, Kwame I, East C (2014) A single incision for harvesting conchal cartilage and temporal fascia indiced cartilagefascia grafts. JAMA Facial Plast Surg 16(5):374.

12. Arora N, Passey JC, Agarwal AK, Bansal R (2017) Type 1 Tympanoplasty by Cartilage Palisade and Temporalis Fascia Technique: A Comparison. Indian J Otolaryngol Head Neck Surg 69(3): 380-384. 
13. Kaya I, Benzer M, Uslu M, Bilgen C, Kirazli T (2017) Butterfly Cartilage Tympanoplasty Long-term Results: Excellent Treatment Method in Small and Medium Sized Perforations. Clin Exp Otorhinolaryngol Clin Exp Otorhinolaryngol 11(2): 23-29.

14. Vadiya S, Parikh V, Shah S, Pandya P, Kansara A (2016) Comparison of Modified Cartilage Shield Tympanoplasty with Tympanoplasty Using Temporalis Fascia Only: Retrospective Analysis of 142 Cases. Sci Cairo 30(2): 80-82.

15. Bilgen C, Turhal G, Ozturk A, Gode S, Kaya I, Kirazli T (2017) Results of endoscopic cartilage tympanoplasty procedure with limited tympanomeatal flap incision. Acta Otolaryngol (Stockh) 137(11): 1174-1177.

16. Simsek E, Ozkan O, Kucur C, Carloglu A (2016) Evaluation of the anatomical and auditory outcomes of minimally invasive cartilage myringoplasty: Our technique and experience. Am J Otolaryngol 37(6): 517-522.

17. Cavaliere M, Panetti M, Iemma M (2014) Tragal cartilage shield tympanoplasty: our technique and results in 612 cases. Acta Otolaryngol (Stockh) 134(9): 890-897.

18. Wiatr M, Wiatr A, Kocoń S, Składzień J (2017) Factors that have an influence on bone conduction thresholds changes after otosurgery in the patients operated on due to the perforation of the tympanic membrane with the preserved ossicular chain. Otolaryngol Pol Pol Otolaryngol 71(4): 26-33.

19. Guo P, Sun W, Wang W (2018) Prognostic and influencing factors of tinnitus in chronic otitis media after tympanoplasty. Eur Arch Otorhinolaryngol 275(1):39-45.

\section{Your next submission with Juniper Publishers will reach you the below assets}

- Quality Editorial service

- Swift Peer Review

- Reprints availability

- E-prints Service

- Manuscript Podcast for convenient understanding

- Global attainment for your research

- Manuscript accessibility in different formats

( Pdf, E-pub, Full Text, Audio)

- Unceasing customer service

Track the below URL for one-step submission https://juniperpublishers.com/online-submission.php 